\title{
Organisational Justice as a Determinant of Organisational Citizenship Behaviour in the Nigerain Work Environment: A Study of Selected Universities in the Niger Delta Region
}

\author{
B. M. Nwibere ${ }^{1}$ \\ ${ }^{1}$ University of Port Harcourt, Nigeria \\ Correspondence: B. M. Nwibere, University of Port Harcourt, Nigeria. E-mail: barrysaro@yahoo.com
}

Received: October 21, 2013

Accepted: March 13, 2014

Online Published: March 21, 2014

doi:10.5539/ijbm.v9n4p191

URL: http://dx.doi.org/10.5539/ijbm.v9n4p191

\begin{abstract}
This study examined the empirical relationship between organizational justice (OJ) and organisational citizenship behaviour (OCB). The sample for the study consisted of two hundred and forty (245) academic members of staff (both teaching and non teaching) from the nine randomly selected universities in the Niger Delta Region of Nigeria. The study adopted the quasi-experimental research design and data were collected from both primary and secondary sources. Data analysis was done by means of the Spearman Rank Order Correlation Coefficient and Multiple Regression Model using the Statistical Package for Social Sciences (SPSS) version 18. The finding revealed a positive and significant relationship between organizational justice and OCB. More specifically, organizational justice was revealed to have a positive and significant influence on the measures of OCB (courtesy, altruism, civic virtue, conscientiousness, and sportsmanship) in the selected Nigerian universities. In view of the results, it behooves the management of Nigerian universities to continuously ensure and promote: fairness in their decisions relating to the distribution of rewards and other organizational favours (distributive justice); fairness of the methods, mechanisms, processes, and procedures used to determine the decisions or outcomes (procedural justice); as well as fairness in the quality of the interpersonal treatment employees receive within the work environment (interactional justice). This is particularly so because when employees perceives that there is emphasis on justice or fairness (procedural justice, distributive justice, and interactional justice) within the organisation, they may reciprocate this gesture by displaying such desirable discretionary work related behaviours that may translate into: (1) taking unusual steps at helping their colleagues with work related task or problem (altruism); (2) going well beyond their usual call of duty in the areas of daily attendance at work, adhering to policies, norms, rules and regulations, etc. (conscientiousness); (3) employees responsibly participating and involving in, or concern about the welfare or success of the organisation (Civic Virtue); (4) the willingness of the employee to tolerate less than ideal situations without complaining (Sportsmanship); and (5) avoiding the occurrence of unnecessary work-related frictions with colleagues (Courtesy). Other practical implications for promotion of organisational justice and enhancing OCB in the workplace are extensively discussed.
\end{abstract}

Keywords: organisational justice, organizational citizenship behaviour, Nigerian universities, Niger Delta region, Nigeria

\section{Context of the Problem}

In recent years, there has been an increase in the research interest in the concepts of organisational justice (herein also referred to as OJ) and organizational Citizenship Behaviour (herein also referred to as OCB) respectively in organizations. This is based on the fact that many scholars believe (and rightly too) that organisational justice and OCB respectively improves overall organizational effectiveness and efficiency. On the one hand, concerned about the sensitivity of issues relating to fairness in any human interaction, Greenberg (1990) introduced the concept of OJ to describe the important role of justice (or fairness) as it directly relates to the work environment. More specifically, Moorman, (1991) maintains that OJ relates to the perception of employees as to whether or not they have been treated fairly at the workplace. The OJ construct has conceptualised as a having three major dimensions: distributive justice, procedural justice, and interactional justice (Greenberg, 1990). 
On the other hand, OCB has been defined as desirable discretionary work related behaviour on the part of an employee, that is not directly or overtly recognized by the formal reward system, and that in the end enhances managerial effectiveness and organisational efficiency (Organ, 1988). Discretionary work related behaviour as used in this context means that the behaviour is neither contained in the employees' job description, nor is it an enforceable requirement of the role, but rather a matter of personal choice or ones volition such that failure to perform them may not attract punishment (Podsakoff et al., 2000, p. 513).

The dominant theoretical basis for most studies on the concept of OCB has been social exchange theory, which is an economic model of human behaviour. Thus, social exchange has been widely cited as an explanation for why employees might act as good organizational citizens, proposing that individuals perform OCB as part of a desire to maintain equitable and favourable workplace relationships that extend beyond the benefits of the more impersonal contractual agreements. It is argued for example, that employees who perceive their supervisors as been fair to them are more likely to reciprocate this gesture with a corresponding positive attitude towards the supervisor, the work, and the work outcomes (Wat \& Shaffer, 2005, p. 407). This argument is similar to what Organ (1988) referred to as "an input to one's equity ratio" as he argues that employees might increase or decrease their levels of OCB as a response to perceived inequity.

Given the relative importance of OJ and OCB in the workplace, several earlier studies have focused on the nature, conceptualisation, antecedents, and consequences of these variables on such desirable work related outcomes as organisational effectiveness, organisational commitment, job satisfaction, intention to stay, and organisational performance. Smith et al., (1983) examined the nature and antecedents of OCB using 422 employees and their supervisors. The researchers asked supervisors to rate how characteristic each of the dimensions of OCB tested were of the employee. The finding of Smith et al., (1983) emphasised the importance of 'citizenship behaviour' in organizations and maintained that such behaviours were not easily explained by the same incentives that induce entry, and conformity to contractual role prescriptions, or high production. The finding of Smith, et al. (1983) also revealed that job satisfaction (as a measure of chronic mood state) had a positive influence on altruism but not generalized compliance; rural background was revealed as having a positive influence on both altruism and generalized compliance; while the influence of leader-supportiveness (as assessed independently by co-workers) and extraversion and neuroticism (as assessed by the Maudsley Personality Inventory) on both altruism and generalized compliance varied (Smith et al., 1983).

Similarly, Konovsky and Organ, (1996) using a sample of 402 professional and administrative employees of a VA hospital examined the influence of dispositional factors such as conscientiousness, agreeableness, and equity sensitivity on contextual work attitudes and OCB. The result revealed that contextual work attitudes predict most forms of OCB. Dispositional variables, particularly conscientiousness was revealed as predicting generalized compliance in particular and OCB in general. Fairness/satisfaction was revealed to have independent effect on OCB, but neither agreeableness nor equity Sensitivity was revealed to affect OCB.

In a study of the relationship between OCB and task performance, the finding of Nasir, et al. (2011) revealed that on the one hand, OCB predicted task performance although on the other hand, contextual variables such as gender and education were also revealed as moderating this relationship. Similarly, earlier empirical evidence revealed that OCB could influence individual and organization performance (Podsakoff \& MacKenzie, 1994; Organ, 1988; Krilowicz \& Lowery, 1996; Podsakoff, Ahearne, \& MacKenzie 1997). Furthermore, using a sample of 302 employees. Farzin et al. (2012) examined the relationship between employees' perception of OJ and leader-member exchange on the OCB among employees of government owned banks in Rasht. Their finding revealed that only interactive justice and leader-member exchange predicted OCB in the banks.

The discussion above is evidence of the fact that there have been several studies on the concepts of OJ and OCB respectively. However, despite these commendable research efforts in this direction something remains lacking: firstly, most studies on OJ and OCB have been largely concentrated in the western world. As at today, there is no known study on the empirical relationship between these variables specifically within the Nigerian work environment. Hence, findings and discussions regarding OJ and OCB like many other US-based behavioural theories have adopted a parochial perspective (Boyacigillar \& Adler, 1991) as they have been presented as though they can be applied universally (Boyacigillar \& Adler, 1991), and this has seriously criticised (Fok et al., 1996). Yet, OJ and OCBs are organization-specific and culture-specific (as they have a cultural component). This implies that without a consideration of the impact of culture during investigation of socially-based concepts such as OCB and OJ, our knowledge on these concepts will remain parochial. For example, it is obvious that variation in cultures will cause a variation in beliefs and values, and by extension differences in views, interpretation of the situations, as well as differences in the preferences for outcomes (Adler, 1989; Hofstede, 1980). Accordingly, it will be safe to say that the concepts of OCB (and its measures) and OJ (and its 
dimensions) has cultural component and are organization-specific (Turnipseed \& Mrukison, 2000; Podsakoff, Niehoff, Mackenzie, \& Williams, 1993). This implies that while investigating socially-based concepts like OCB and $\mathrm{OJ}$, it is necessary to examine its contextual dimensions under varying societal cultures as well as the economic institutional framework (Farh, Zhong, \& Organ, 2004; Farh, Early, \& Lin, 1997). Based on the above, it is obvious that an understanding of the relationship between OJ and OCB in a non western context like Nigeria is begging for attention and hence merits further investigation especially in an era of globalization, when managers are caused to attend to issues of culture and diversity. In support of this point Hofstede, $(1984 ; 1980)$ also emphasized that any comparative study across cultural lines must consider cultural differences.

This study therefore is an answer to the earlier call by Podoskaff et al. (2000) that research was needed on the potential impact that cultural context might have on OCB. Besides, an increasing growth of OCB in a non-western context corresponds to the call that more attention needs to be focused on cross-cultural issues and their implications for theories of behaviour. Nevertheless, it is remarkable that our understanding of OJ and OCB beyond a non western context seems so parochial and fragmental as something remains lacking. There is a dire and continuous need for an integrated and comprehensive understanding of OJ and OCB research in a non western context. To fill this gap in the literature, this study examines the relationship between OJ and OCB in selected universities in the Niger Delta Region of Nigeria.

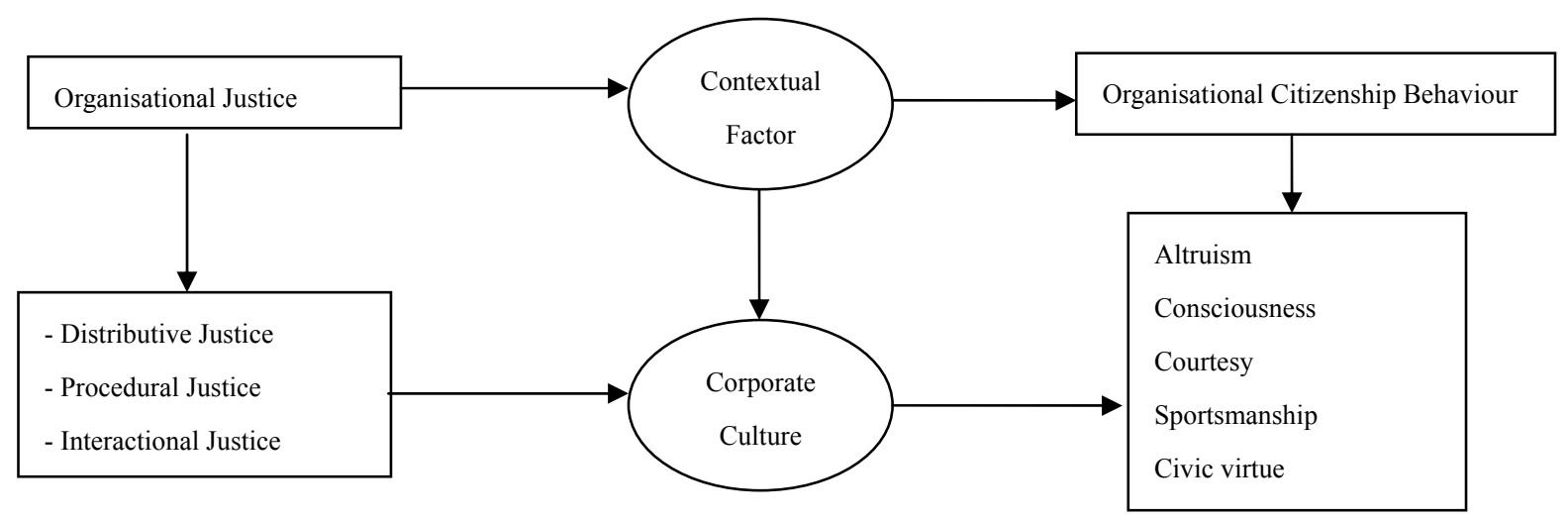

Figure 1. A conceptual framework for analyzing the relationship between OJ and OCB as well as the moderating role of corporate culture

Source: conceptualised by the researcher.

\section{Review of Related of Literature}

\subsection{Organisational Justice (OJ) Defined}

Organizational justice is the concept used to to describe the important role of fairness as it directly relates to the work environment. More specifically, organizational justice relates to the perception of employees as to whether or not they have been treated fairly at the workplace (Moorman, 1991:845). Three most common dimensions of organisational justice that have been identified in the management literature includes: procedural justice, distributive justice, and interactional justice. Distributive justice relates to the fairness of the outcome or decision. There are many different definitions of what is "fair" in the distribution of rewards and the research evidence has demonstrated that the definition of fairness is influenced by the prevailing culture. According to Leventhal, (1976), people use three major justice rules to determine outcome justice: the needs rule, the contributions rule (equity rule), and the equality rule. The first definition of what is "fair" in the distribution of rewards (equity rule) is based on the notion of merit. The emphasis here is that hard working employees or employees that perform the most should earn the greatest work related rewards. This is called the merit or equity norm. The purpose of outcomes or decisions based on the equity rule is to achieve high productivity and a high level of performance. The second definition (the needs rule) is based on the notion of equality. The emphasis here is that every member of the organisation should earn the same share of rewards, regardless of effort. The equality rule is used when the goal is to preserve social harmony. The third definition of fairness is based on the need norm. The emphasis here is that every member of the organisation should receive rewards in proportion to their needs (Gilliland \& Chan, 2001). The needs rule is applied when the objective is to foster personal welfare. 
Earlier empirical research has shown some cross-cultural variation in the preferred basis for outcome distribution and the foundation for defining justice of fairness, with Americans favouring the principle of equity (Greenberg, 1982; Storey, 2000), Indians of need (Storey, 2000), and Dutch of equality (Storey, 2000); the equality norm is stronger in Nigeria and many other African countries. The government emphasis on quota system as well as band wagon annual promotion policy adopted in the Nigerian civil service may have accounted for this finding. The Scandinavian countries have a long tradition of distributing rewards based on the equality norm. This is also true of Asian countries such as Japan and China (Greenberg, 1982). This may be explained by the fact that going by the Hofstede (2001) model, both of these cultures would be classified as collectivist.

It is relevant to note that the fairness of work related rewards or decisions (distributive justice) is not the only relevant issue to an employee; the faimess the processes, methods, procedures, and mechanisms used to determine the work related rewards (procedural justice) is equally important. Procedural justice as used in this context describes the extent to which fair methods, procedures, mechanisms, and processes are spelt out and adhered as well as the extent to which individuals see their leaders as being fair, sincere and logical or rational in what they do (Folger \& Cropanzano, 1998, p. 26; Skarlicki \& Latham, 1996; Ivancevich \& Matteson, 2002). Closely allied to distributive justive and procedural justice, the third dimension, interactional justice, describes people's sensitivity to "the quality of interpersonal treatment they receive during the enactment of organisational procedures" (Bies \& Moag, 1986, p. 44). This concept deals with the extent to which an employee feels respected by their supervisor or employer. In addition to respect and truthfulness, other salient attributes of interactional justice include propriety of questions, and justification (Bies \& Moag, 1986, p. 44).

Taken together, distributive justice relates to the fairness of the work related rewards or decision; and procedural justice focus on the fairness of the processes, methods, mechanisms, methods, and procedures used to determine the work related rewards or outcome. Since procedural, distributive, and interactional justice play a role in an individual's perception of the fairness of treatment, they all form part of the OJ construct.

\subsection{Organizational Citizenship Behaviour (OCB) Defined}

There have been several definitions of OCB. Simply put, OCB is defined as desirable discretionary work related behaviour on the part of an employee, that is not directly or overtly recognized by the formal reward system, and that in the end enhances organisational effectiveness and managerial efficiency (Organ, 1988; Pau Jung \& Hong, 2008, p. 794). Discretionary work related behaviour as used in this context mean that the behaviour is neither contained in the employees the job description, nor is it an enforceable requirement of the role rather, the behaviour is a matter of personal choice or volition, such that failure to perform them may not attract punishment (Podsakoff et al., 2000, p. 513; Graham, 1989).

A review of related literature on this concept also reveal that although the growing interest in OCB is a welcome development, there is still a lack of consensus about the dimensions of this construct as over thirty potentially different forms of OCB. However, a closer look at some of these dimensions reveals a great deal of conceptual overlap between the constructs. For the purpose of this study, we distinguish between five popular dimensions of OCB that has been identified in the management literature. They include: firstly, helping a colleague with work related task or problem (altruism); secondly, going well beyond their usual call of duty in the areas of daily attendance at work, adhering to policies, norms, rules and regulations, etc. (conscientiousness); thirdly, responsibly participating and involved in, or concerned about the welfare or success of the organisation (Civic Virtue); fourthly, behaviours indicating the willingness of the employee to tolerate less than ideal situations without complaining (Sportsmanship); and finally, avoiding the occurrence of unnecessary work-related frictions with colleagues (Courtesy) (Organ 1988; Lepine, Erez \& Johnson, 2002; De Nicolis Bragger et al., 2005, p. 305). Besides courtesy, civic virtue, conscientiousness, sportsmanship, and altruism, other dimensions of OCB identified in the management literature include: self-development, helping behaviour, individual initiative, organizational loyalty, and organizational compliance. The five dimensions offered by Organ (1988) and earlier discussed above are adopted for the purpose of this study.

\section{Research Methods}

\subsection{Operational Measures of Variables}

The independent variable in this study is OJ. The dimensions of this variable adopted for this study include: procedural justice, distributive justice, interactional justice. OJ was operationalised using the OJ Questionnaire. The nine (9) items used in operationalising distributive justice were adapted from the earlier studies of Nichoff and Moorman (1993); and Price and Mueller (1986). The seven (7) items used in operationalising procedural justice were adapted from the earlier studies of Elovainio, Kivimäki, and Vahtera (2002); Nichoff and Moorman 
(1993); and Moorman (1991). The ten (10) items used in operationalising interactional justice were adapted from the earlier studies of Elovainio, Kivimäki, and Vahtera (2002); Moorman, (1991); Nichoff and Moorman (1993) and Price and Mueller (1986). Sample items for each of these dimensions of OJ are indicated in the appendix of this paper. All the three dimensions of organisational justice were measured on a 5- point Likert type scale. The response mode ranges from $5=$ strongly agree to $1=$ strongly disagree (see appendix).

The dependent variable for this study is OCB. The components of this construct adopted for this study is based on the earlier study of Organ, (1988) and includes: conscientiousness, civic virtue, sportsmanship, altruism, and courtesy. The scales used to operationalise the five components of OCB adopted in this study were adapted from the OCB Questionnaire by Podsakoff et al. (2000); Organ (1988). The conceptual definitions of each of these variables were used to generate the items in the OCB Questionnaire. Sample items for each of these measures of OCB are indicated in the appendix of this paper. All the measures of OCB were measured on a 5-point Likert type scale. The response mode ranges from $5=$ strongly agree to $1=$ strongly disagree.

Corporate culture was examined as the moderating variable in this study. Based on the study of Dennison, (1990) corporate culture was measured along four dimensions: involvement index, consistency index, adaptability index, and mission index. Two questions were used to measure each of these dimensions. Sample items for each of these dimensions of corporate culture are indicated in the appendix of this paper.

All the four dimensions of culture were measured on a 5-point Likert type scale. The response mode ranges from $5=$ strongly agree to $1=$ strongly disagree.

\subsection{Test of Validity and Reliability}

To assess the validity of the survey instrument, sample copies of the questionnaire were given to some of my colleagues. Their suggestions and/or criticisms were noted and used to modify the instrument. To further ensure validity, the data were collected from multiple sources and thereafter triangulated. To ensure reliability, two major steps were taken. Firstly, data from multiple sources (questionnaire, interview, and a review of related literature) were triangulated. Secondly, the internal reliability of the survey instrument was assessed by means of Cronbach Alpha Coefficients, using SPSS. Under this procedure, only items that returns alpha values of 0.7 and above were considered. The table below indicates the internal consistency (Cronbach's alpha values) for each of the variables in this study.

Table 1. The internal consistency/cronbach's alpha values for OJ

\begin{tabular}{llcc}
\hline & Variables & Number of items & Cronbach $\boldsymbol{\alpha}$ \\
\hline 1 & Distributive Justice & 5 & 0.893 \\
2 & Procedural Justice & 7 & 0.809 \\
3 & Interactional Justice & 6 & 0.837 \\
4 & Perceptions of Organizational Justice & 18 & 0.856 \\
\hline
\end{tabular}

Source: survey data, 2013.

Table 2. The internal consistency/ cronbach's alpha values for OCB

\begin{tabular}{llcc}
\hline & Variables & Number of items & Cronbach $\boldsymbol{\alpha}$ \\
\hline 1 & Conscientiousness & 5 & 0.71 \\
2 & Courtesy & 5 & 0.75 \\
3 & Sportsmanship & 5 & 0.81 \\
4 & Altruism & 5 & 0.91 \\
5 & Civic virtues & 4 & 0.79 \\
& OCB & 24 & 0.858 \\
\hline
\end{tabular}

Source: survey data, 2013.

\subsection{Data Analysis Technique}

To empirically evaluate the relationships between the independent variable (organisational justice and its components) and the independent variable (OCB) as well as the effect of the moderating variable (corporate culture), the Spearman Rank-order correlation co-efficient (spearman's rho) statistical technique and the Multiple Regression Analysis of Variance (MANOVA), using the statistical package for social sciences (SPSS) 
were employed. The Spearman Rank-order correlation co-efficient (spearman's rho) statistical technique was used to analyse the influence of OJ on OCB. On the other hand, the Multiple Regression Analysis of Variance (MANOVA) using SPSS was used test the moderating role of corporate culture on the relationships between OJ and OCB. As emphasised earlier, we are assuming that the relationship between OJ and OCB may be direct or moderated by the corporate culture. In recent years, multi-variate statistical tools have been applied with increasing frequency to research problems in recognition of the fact that many of the problems we encounter are more complex than the problems Bi-Variate Models can explain (Cooper \& Schindler, 2010). According to Hair, et al (1998), Multi-Variate Analysis are "those techniques which focus upon, and bring out in bold relief, the structure of simultaneous relationships among three or more variables or phenomena." The choice of these statistical techniques is informed by their amenability to the type or level of data that were collected.

\section{Research Results and Analysis of Findings}

This section focuses on the statistical testing of the hypotheses using the collected data. This analysis will provide the basis for the acceptance or rejection of the formulated hypotheses.

Table 3. Results of regression analysis on the relationship between OJ and OCB

Model summary

\begin{tabular}{lllll}
\hline Model & $\mathrm{R}$ & $\mathrm{R}$ Square & Adjusted R Square & Std. Error of the Estimate \\
\hline 1 & $.870^{\mathrm{a}}$ & .754 & .470 & .46240 \\
\hline
\end{tabular}

a: Predictors (constant), organisational justice.

\section{ANOVA $^{\mathrm{b}}$}

\begin{tabular}{lllllll}
\hline Model & & Sum of Squares & df. & Mean Square & F & Sig. \\
\hline 1 & Regression & 46.435 & 1 & 46.435 & 217.176 & $.000^{\mathrm{a}}$ \\
& Residual & 51.965 & 243 & .214 & & \\
& Total & 98.391 & 244 & & & \\
\hline
\end{tabular}

a: Predictors (constant), organisational justice.

b: Dependent variable: organizational citizenship behavior.

Coefficients $^{\mathrm{a}}$

\begin{tabular}{|c|c|c|c|c|c|c|}
\hline \multirow[t]{2}{*}{ Model } & & \multicolumn{2}{|c|}{ Unstandardized Coefficients } & \multirow{2}{*}{$\begin{array}{l}\text { Standardized } \\
\text { Coefficients } \\
\text { Beta }\end{array}$} & \multirow[t]{2}{*}{$\mathrm{T}$} & \multirow[t]{2}{*}{ Sig. } \\
\hline & & $\mathrm{B}$ & Std. Error & & & \\
\hline \multirow[t]{2}{*}{1} & Constant & .875 & .147 & & 5.953 & .000 \\
\hline & $\begin{array}{l}\text { Organizational } \\
\text { Justice }\end{array}$ & .710 & .048 & .687 & 14.737 & .000 \\
\hline
\end{tabular}

a: Dependent variable: organizational citizenship behavior.

Results of data analysis indicate that the adjusted coefficient of determination $\left(R^{2}\right)$ is 0.470 . This implies that the organisational justice accounts for about 47.0 percent of the variation in OCB. The results of data analysis also indicate that F-calculated is 217.176 and the corresponding significance value is 0.000 which is less than 0.01 . This implies that the model is significant.

Table 4. Results of regression analysis between OJ and OCB

\begin{tabular}{llllllll}
\hline Independent variable & $\mathbf{R}$ & $\mathbf{R}^{2}$ & Adjusted $\mathbf{R}^{2}$ & F & Prob. & T & Prob. \\
\hline Organisational Justice & .870 & .754 & .470 & 217.176 & .000 & 5.953 & .000 \\
\hline
\end{tabular}

Dependent variable: OCB.

The value of t-calculated is 5.953 and the corresponding significant value of 0.000 is less than 0.01 . Hence, we reject the null hypothesis and conclude that organisational justice has a strong positive and significant effect on 
OCB $(\mathrm{t}=5.953, \mathrm{p}<0.01)$.

This study also examined the specific relationships between the dimensions of organisational justice (procedural justice; distributive justice; and interactional justice) and the measures of OCB (altruism, conscientiousness, courtesy, sportsmanship, and civic virtue). The discussion that follows takes a look at the findings after data analysis.

Table 5. Results of Spearman rank correlation between the dimensions of OJ and measures of OCB

\begin{tabular}{|c|c|c|c|c|c|c|c|c|c|c|c|c|}
\hline \multirow[t]{3}{*}{ Type } & \multirow[t]{3}{*}{ Variables 1} & \multirow[t]{3}{*}{ Statistics } & \multirow{3}{*}{$\begin{array}{l}\text { Distributive } \\
\text { Justice }\end{array}$} & \multirow{3}{*}{$\begin{array}{l}\text { Procedural } \\
\text { Justice }\end{array}$} & \multirow{3}{*}{$\begin{array}{l}\text { Interactional } \\
\text { Justice }\end{array}$} & \multirow[t]{3}{*}{ Altruism } & \multirow[t]{3}{*}{ Conscientiousness } & \multirow[t]{3}{*}{ Courtesy } & \multirow[t]{3}{*}{ Sportsmanship } & \multirow{3}{*}{$\begin{array}{l}\text { Civic } \\
\text { virtue }\end{array}$} & \multirow{3}{*}{$\begin{array}{l}\text { Organisational } \\
\text { Citizenship } \\
\text { Behaviour }\end{array}$} & \multirow{3}{*}{$\begin{array}{l}\text { Organizational } \\
\text { Justice }\end{array}$} \\
\hline & & & & & & & & & & & & \\
\hline & & & & & & & & & & & & \\
\hline Spearman's & Distributive & Correlation & 1.000 & & & & & & & & & \\
\hline \multirow[t]{32}{*}{ rho } & Justice & Coefficitent & & & & & & & & & & \\
\hline & & Sig.(2-tailed)N & 245 & & & & & & & & & \\
\hline & Procedural Justice & Correlation & $.360 * *$ & 1.000 & & & & & & & & \\
\hline & & Coefficitent & .000 & & & & & & & & & \\
\hline & & Sig.(2-tailed)N & 245 & 245 & & & & & & & & \\
\hline & Interactional & Correlation & $.195 * *$ & $.545^{* *}$ & 1.000 & & & & & & & \\
\hline & Justice & Coefficitent & .000 & .000 & & & & & & & & \\
\hline & & Sig.(2-tailed)N & 245 & 245 & 245 & & & & & & & \\
\hline & Atruism & Correlation & $.376^{* *}$ & $.630 * *$ & $.522 * *$ & 1.000 & & & & & & \\
\hline & & Coefficitent & .000 & .000 & .000 & & & & & & & \\
\hline & & Sig.(2-tailed)N & 245 & 245 & 245 & 245 & & & & & & \\
\hline & Conscientiousness & Correlation & $.364 * *$ & $.628 * *$ & $.503 * *$ & $.944 * *$ & 1.000 & & & & & \\
\hline & & Coefficitent & .000 & .000 & .000 & .000 & & & & & & \\
\hline & & Sig.(2-tailed)N & 245 & 245 & 245 & 245 & 245 & & & & & \\
\hline & Courtesy & Correlation & $.360 * *$ & $.599 * *$ & $.510 * *$ & $.935 * *$ & .949 & 1.000 & & & & \\
\hline & & Coefficitent & .000 & .000 & .000 & .000 & .000 & 245 & & & & \\
\hline & & Sig.(2-tailed)N & 245 & 245 & 245 & 245 & 245 & & & & & \\
\hline & Sportsmanship & Correlation & $.428 * *$ & $.649 * *$ & $.479^{* *}$ & $.665 * *$ & .661 & .672 & 1.000 & & & \\
\hline & & Coefficitent & .000 & .000 & .000 & .000 & .000 & .000 & & & & \\
\hline & & Sig.(2-tailed)N & 245 & 245 & 245 & 245 & 245 & 245 & 245 & & & \\
\hline & Civic virtue & Correlation & $.467 * *$ & $.647 * *$ & $.455 * *$ & $.627 * *$ & $.645 * *$ & $.639 * *$ & $.842 * *$ & 1.000 & & \\
\hline & & Coefficitent & .000 & .000 & .000 & .000 & .000 & .000 & .000 & & & \\
\hline & & Sig.(2-tailed)N & 245 & 245 & 245 & 245 & 245 & 245 & 296 & 245 & & \\
\hline & Corporate & Correlation & $.345 * *$ & $.546 * *$ & $.315 * *$ & $.518^{* *}$ & $.556 * *$ & $.544 * *$ & $.731 * *$ & $.779 * *$ & & \\
\hline & Culture & Coefficitent & .000 & .000 & .000 & .000 & .000 & .000 & .000 & .000 & & \\
\hline & & Sig.(2-tailed)N & 245 & 245 & 245 & 245 & 245 & 245 & 245 & 245 & & \\
\hline & Organisational & Correlation & $.412 * *$ & $.641 * *$ & $.518 * *$ & $.947 * *$ & $.933 * *$ & $.934 * *$ & $.643 * *$ & $.616^{* *}$ & 1.000 & \\
\hline & Citizenship & Coefficitent & .000 & .000 & .000 & .000 & .000 & .000 & .000 & .000 & & \\
\hline & Behaviour & Sig.(2-tailed)N & 245 & 245 & 245 & 245 & 245 & 245 & 245 & 245 & 245 & \\
\hline & Organizational & Correlation & $.548 * *$ & $.763 * *$ & $.531 * *$ & $.670 * *$ & $.659 * *$ & $.669 * *$ & $.862 * *$ & $.877^{* *}$ & $.717^{* *}$ & 1.000 \\
\hline & Justice & Coefficitent & .000 & .000 & .000 & .000 & .000 & .000 & .000 & .000 & .000 & \\
\hline & & Sig.(2-tailed)N & 245 & 245 & 245 & 245 & 245 & 245 & 296 & 245 & 245 & 245 \\
\hline
\end{tabular}


The first hypothesis sought to examine the relationship between distributive justice and organisational citizenship behaviour within the Nigeria work environment and the university system to be specific. Hence, it was hypothesised that: there is no significant relationship between distributive justice and organisational citizenship behaviour. This hypothesis was tested using the Spearman's Rank Order correlation coefficient statistical technique. As can be seen from the analysis of collected data (see table 5 above) there was a strong, positive correlation between distributive justice and OCB which was statistically significant. The specific values for the relationship between distributive justice and the measures of OCB are as follows: altruism $\left(r_{s}=0.376\right.$, $\mathrm{P}<0.01)$; conscientiousness $\left(r_{s}=0.364, \mathrm{P}<0.01\right)$; civic virtue $\left(r_{s}=0.467, P<0.01\right)$; courtesy $\left(r_{s}=0.360, \mathrm{P}<0.01\right)$, and sportsmanship $\left(r_{s}=0.428, \mathrm{P}<0.01\right)$. Based on the finding above, it was concluded that distributive justice enhances OCB within the Nigerian university system.

The second hypothesis sought to examine the relationship between procedural justice and OCB within the Nigeria work environment and the university system to be specific. As can be seen from the analysis of collected data (see table 5 above) there was a strong, positive and statistically significant correlation between procedural justice and OCB. The specific values for the relationship between procedural justice and the measures of OCB are as follows: altruism $\left(r_{s}=0.630, P<0.01\right)$; Conscientiousness $\left(r_{s}=0.628, P<0.01\right)$; civic virtue $\left(r_{s}=0.647\right.$, $P<0.01)$; courtesy $\left(r_{s}=0.599, \mathrm{P}<0.01\right)$, and sportsmanship $\left(r_{s}=0.649, \mathrm{P}<0.01\right)$. Based on the finding above, it was concluded that procedural justice enhances OCB within the Nigerian university system.

The third hypothesis sought to examine the relationship between interactional justice and OCB within the Nigeria work environment and the university system to be specific. As can be seen from the analysis of collected data (see table 5 above) there was a strong, positive and statistically significant correlation between distributive justice and OCB. The specific values for the relationship between interactional justice and the measures of OCB are as follows: altruism $\left(\mathrm{r}_{\mathrm{s}}=0.522, \mathrm{P}<0.01\right)$; Conscientiousness $\left(\mathrm{r}_{\mathrm{s}}=0.503, \mathrm{P}<0.01\right)$; civic virtue $\left(\mathrm{r}_{\mathrm{s}}=0.455\right.$, $\mathrm{P}<0.01)$; courtesy $\left(\mathrm{r}_{\mathrm{s}}=0.510, \mathrm{P}<0.01\right)$, and sportsmanship $\left(\mathrm{r}_{\mathrm{s}}=0.479, \mathrm{P}<0.01\right)$. Based on the finding above, it was concluded that interactional justice enhances OCB within the Nigerian university system.

The fourth hypothesis sought to examine the moderating role of corporate culture on the relationship between the independent variable (OJ) and the dependent variable (OCB) within the Nigerian university system. This hypothesis was tested using the multivariate analysis of variance (MANOVA) statistical technique (specifically, multiple regression analysis) using SPSS. Data analysis (see table below) however, revealed that corporate culture played a major moderating roles in the relationships between organizational justice and OCB $\left(r_{s}=0.570\right.$, $\mathrm{P}<0.01)$.

Table 6. Partial correlation analysis showing the moderating effect of corporate culture on the relationship between organisational justice and OCB

\begin{tabular}{|c|c|c|c|c|c|}
\hline $\begin{array}{l}\text { control } \\
\text { variables }\end{array}$ & Variables & Statistics & $\begin{array}{l}\text { organizational } \\
\text { justice }\end{array}$ & $\begin{array}{l}\text { organizational } \\
\text { citizenship } \\
\text { behavior }\end{array}$ & $\begin{array}{l}\text { corporate } \\
\text { culture }\end{array}$ \\
\hline \multirow[t]{9}{*}{-non- } & organizational justice & Correlation & 1.000 & .687 & .697 \\
\hline & & significance(2-tailed) & . & .000 & .000 \\
\hline & & Df & 0 & 243 & 243 \\
\hline & organizational & Correlation & .687 & 1.000 & .467 \\
\hline & citizenship behavior & significance(2-tailed) & .000 & . & .000 \\
\hline & & Df & 243 & 0 & 243 \\
\hline & corporate culture & Correlation & 697 & .467 & 1.000 \\
\hline & & significance(2-tailed) & .000 & .000 & . \\
\hline & & Df & 243 & 243 & 0 \\
\hline \multirow{6}{*}{$\begin{array}{l}\text { corporate } \\
\text { culture }\end{array}$} & organizational justice & Correlation & 1.00 & .570 & \\
\hline & & significance(2-tailed) & . & .000 & \\
\hline & & Df & 0 & 242 & \\
\hline & organizational & Correlation & .570 & 1.000 & \\
\hline & citizenship behavior & significance(2-tailed) & .000 & . & \\
\hline & & Df & 242 & 0 & \\
\hline
\end{tabular}

a: Cells constain zero-order (Pearson) correlations. 
Based on the finding above, it was concluded corporate culture moderates the influence of organizational justice on OCB within the Nigerian university system.

\section{Discussion of Findings and Conclusion}

This study examined the empirical relationship between employees' perceptions of OJ and OCB within the Nigerian university system. As can be seen from the analysis of collected data, employees' perception of OJ was revealed to have a strong positive and significant influence on OCB. This finding supports the earlier findings of Farh, Podasakoff, and Organ, (1990); Organ (1988); Podsakoff et al. (2000); Martin and Bies, (1991); Niehoff and Moorman, (1993); Konovsky and Folger, (1991); and Moorman, (1991) all of which had also reported that employees perception of fairness predicts the various dimensions of OCB. For example, the earlier studies of the motivational basis of OCB by Organ, (1988) and Young, (2010, p. 638) also revealed that employees' perception of fairness/ justice predicts OCB. Based on the social exchange perspective as earlier described above, Organ, (1988) also proposed that employees exhibit discretionary work related behaviour (herein also referred to as OCB) to reciprocate the fair treatment they receive from their organizations (Young, 2010, p. 638). To further buttress this point, Podsakoff et al. (2000) argued that OCB will naturally increase when the employees perceive their relationship with their supervisors as cordial and that their supervisor is fair to them.

This study also examined the specific relationships between the dimensions of OJ and the measures of OCB. Firstly, as can be seen from the analysis of collected data, distributive justice has a significant positive influence on the measures of OCB (altruism, conscientiousness, civic virtue, sportsmanship, and courtesy). One explanation for this finding may be that employees sees the continuous and fair distribution of organizational favours as the organization commitment to them and would reciprocate this gesture with a corresponding positive attitude and behaviour at work. Employees continuously evaluate the way they are treated by the organization and reciprocate their perception of these treatments in their attitudes, behaviour and emotions at work.

Similarly, the analysis of collected data also reveals that procedural justice has a significant positive influence on all the measures of OCB. These findings supports the earlier findings of Alexander and Ruderman (1987) which reported that the practice of procedural justice predicts both the turnover intentions of employees and the degree to which there existed conflict or harmony in the work setting. One explanation for this finding is the fact that when employees are satisfied that the methods, mechanisms, guidelines and/or the processes used to make decisions that influence them are just (Ang et al., 2003, p. 563), they may reciprocate this gesture by displaying such desirable discretionary work related behaviours as: courtesy, conscientiousness, civic virtue, altruism, and sportsmanship.

The findings of this study also revealed that interactional justice has a significant positive influence on all the measures of OCB (courtesy, conscientiousness, civic virtue, altruism, and sportsmanship). These findings are in line with the earlier findings of Farzin (2012), Organ (1988); Young (2010); and Podsakoff et al. (2000). This finding suggest that employees are not only concerned about fairness in the distribution of work related rewards and the fairness of the methods, mechanisms, guidelines and/or the processes used to make decisions that influence them, but they are also concerned about the quality of interpersonal treatment they received during the enactment of procedures and tie perceptions of justice to it (Lau, 2008, p. 15). This finding also suggests that perceptions of procedural justice are a product of employees' perception of the organization's procedures and the manner in which they are implemented (Wat \& Shaffer, 2005, p. 409). This implies that that when employees are sure of fairness in their assessments of the quality of interpersonal treatment they received during the enactment of organisational procedures, they may reciprocate this gesture by displaying such discretionary behaviours as: courtesy, conscientiousness, civic virtue, altruism, and sportsmanship.

To buttress the findings of this study, Podsakoff, et al. (2000) maintains that if the employees are treated fairly, and the supervisors also have a cordial relationship with them, the amount of OCB will naturally increase. This by extension implies that besides being important predictor of key job attitude, perception of organisational justice or fairness may also promote effectiveness in organisations by influencing an individual employee's decision to perform OCBs. The earlier study of Greenberg, (1990) also reported relationships between employees' perception of fairness and positive organisational attitudes. Similarly, Organ, $(1988 ; 1990)$ has suggested that employees perception of fairness in the workplace are instrumental in developing the their levels of faith and trust in the organisation both of which are needed to ignite desirable or beneficial, yet discretionary, work related behaviours that define OCB.

From the discussions above, it obvious that employees' perception of organisational justice will promote such desirable discretionary work related behaviour such as: (1) helping colleague with work related task or problem 
(altruism); (2) going well beyond their usual call of duty in the areas of daily attendance at work, adhering to policies, norms, rules and regulations, etc. (conscientiousness); (3) responsibly participating and involving in, or is concerned about the welfare or success of the organisation (civic virtue); (4) employees' willingness tolerate less than ideal situations without complaining (sportsmanship); and (5) avoiding the occurrence of unnecessary work-related frictions with colleagues (courtesy). Thus, employees' perception of organisational justice will enhance what Graham, (1991) described as the responsibilities that employees have as "citizens" of an organization.

Data aanalysis also revealed that the prevailing corporate culture plays a major moderating role in the relationship between OJ and OCB. This finding provides further support to past research that suggests that corporate culture (e.g., a fair working environment-Organ \& Ryan, 1995) is important for promoting the performance or display of OCBs. On explanation for this finding is the fact that variation in cultures will cause a variation in beliefs and values, and by extension differences in views, interpretation of the situations, as well as differences in the preferences for outcomes (Adler, 1989; Hofstede, 1980). Given that the concept of OCB (and its dimensions) has cultural component and are organization-specific (Podsakoff, Niehoff, Mackenzie, \& Williams, 1993; Turnipseed \& Mrukison, 2000) as revealed in this study, it implies that research efforts at investigating socially-based concept like $\mathrm{OCB}$, needs to examine its contextual dimensions under varying societal culture and economic institutional framework (Farh, Zhong \& Organ, 2004). This finding therefore is buttresses the earlier call by Podoskaff et al. (2000) that research was needed on the potential impact that cultural context might have on OCB.

It is relevant to note that as Gilliland, Benson, and Schepers (1998) proposed, injustice has a much greater impact than justice on subsequent attitudes, emotions, and behaviour. Once an injustice threshold has been exceeded, there is no way to counteract the feelings of injustice. Even when employers try to make up for an injustice with fairer subsequent treatment they cannot undo the harm caused by the perceived injustice. Gilliland and Chan (2001) suggested that injustice, once experienced, leads to retaliation or reduced effort or motivation, whereas perceptions of justice lead to extra effort and feelings of inclusion and contribution. Currently, justice and injustice are considered two ends of a single continuum, with equal and opposite reactions. But many individuals experience justice quite differently from the way they experience injustice. The experience of injustice has a tendency to linger for a long time, sometimes over decades. Many of us remember for years an instance in which we were "screwed" by an employer, yet we tend to take just treatment for granted. We are also sensitive to incidents where valued co-workers are "screwed." We wonder if the same thing could happen to us, thus experiencing injustice vicariously.

\section{Recommendations}

Based on the discussion of findings and conclusions above, the following recommendations are made: Firstly, the management of Nigerian universities should take steps to ensure that there is fairness in the distribution of organisational rewards, inducements and favours that the employees receives in exchange for their contributions at work (distributive justice), as this is capable of enhancing their display of OCBs. This is particularly so as individuals naturally form perceptions of what constitutes a fair balance or trade-off of inputs and outputs by continuously comparing their inputs (or efforts) and the inputs (or efforts) of their colleagues viz-a-viz the outputs (or rewards) they receive and the outputs (or rewards) of their colleagues on similar jobs in the organization. It is also a fact of life that as individuals, we are also influenced by families, friends, colleagues, partners in establishing these benchmarks and our own responses to them in relation to our own ratio of inputs to outputs. Within the work environment, employees continuously evaluate whether there exist equity between their efforts (in terms of their performance) and the reward they receive. Equity in this context describes the employees' perception of fairness in the effort or performance-rewards relationship. Employees will compare their efforts and rewards with those of others in similar work situations. A fair or equitable situation is one in which people with similar inputs experience similar reward outcomes. This theory of motivation is based on the assumption that individuals are motivated by a desire to be equitably treated at work (Baridam \& Nwibere, 2008).

Secondly, enterprise managers should ensure that organisational decisions are based on fair methods, mechanisms and guidelines and the processes used to make decisions are just. In other words, the methods, guidelines, and processes used to make decisions in the organisation should be seen by all concerned as been fair.

Thirdly, given that people are always concerned about the quality of interpersonal treatment they received during the enactment of procedures and tie their perceptions of justice to it (Lau, 2008, p. 15), it behoves on 
enterprise managers to ensure fairness in the quality of interpersonal treatment given to employees during the enactment of procedures as this is capable of enhancing their display of OCB. Nigerian enterprise managers should adjust, modify and/or replace all policies and procedures that limit employees' participation/involvement in the decision making process. They should develop strategies that would provide required terms to respect, build trust, and accommodate employees' suggestions in the process of making decision. The most important step in this direction will be to design strategies and procedures that facilitate employees' participation/involvement in the decision making process.

Finally, borrowing from the suggestion of Bies and Shapiro (1988) we recommend that a sense of concern over perceived injustice can be resolved if the manager takes definite steps in providing the unfairly treated individual with a social account such as an explanation or better still, an apology. Human beings by nature expect events that affect them to be explained. Naturally, if individuals do not receive any explanation, they doubt whether they have been treated in accordance with a socially rooted expectation for fair processes in human interaction (Weaver, 2001). Given that respect is said to be reciprocal (given and taken) and is earned, it can be argued that in the workplace, respect and concern constitute informal social goods, and failing to receive them is seen as a violation of justice expectations.

In view of the results, it behooves the management of Nigerian universities to continuously ensure and promote fairness in decisions relating to the distribution of organizational favours (distributive justice), fairness of the processes, methods, mechanisms, and procedures used to determine the decision or outcome (procedural justice), as well as fairness in the quality of the interpersonal treatment people receive within the organisation (interactional justice). This is particularly so because when employees perceives that there is emphasis on organisationnal justice within the organisation, they may reciprocate this gesture by displaying such desirable discretionary work related behaviours that have the effect of helping colleagues with work related task or problem (altruism); discretionary work related behaviours on the part of the employee that go well beyond their usual call of duty, in the areas of attendance, obeying rules and regulations, taking breaks, and so forth (Conscientiousness); behaviour that indicates that the employee responsibly participates in, is involved in, or is concerned about the life of the company (civic virtue); behaviours that indicates the willingness of the employee to tolerate less than ideal situations without complaining (Sportsmanship); and behaviours aimed at preventing work-related friction with others from occurring (Courtesy).

\section{References}

Adler, N. J. (1989). Cross-cultural interaction: The International Comparison Fallacy? Journal of International Business Studies, 515-537. http://dx.doi.org/10.1057/palgrave.jibs.8490367

Alexander, S., \& Ruderman, M. (1987). The Role of Procedural and Distributive Justice In Organization Behaviour. Social Justice Research, 1(2), 177-198. http://dx.doi.org/10.1007/BF01048015

Ang, S., Van Dyne, L., \& Begley, T. M. (2003). The Employment Relationships of Foreign Workers Versus Local Employees: A field study of Organizational Justice, Job Satisfaction, Performance and OCB. Journal of Organizational Behaviour, 24, 561-583. http://dx.doi.org/10.1002/job.202

Baridam, D. M., \& Nwibere, B. M. (2008). Understanding and Managing Organisational Behaviour. Sherbrooke Associates, Port Harcourt.

Bies, R. J., \& Moag, J. F. (1986). Interactional Justice: Communication Criteria of Fairness. In R. J. Lewicki, B. H. Sheppard, \& M. H. Bazerman (Eds.), Research on Negotiations in Organizations (Vol. 1, pp. 43-55). Greenwich, CT: JAI press.

Bies, R. J., \& Shapiro, D. L. (1988). Voice and Justification: Their Influence on Procedural Fairness Judgments. Academy of Management Journal, 31(3), 676-685. http://dx.doi.org/10.2307/256465

Boyacigillar, N. A., \& Adler, N. J. (1991). The Parochial Dinosaur: Organizational Science In A Global Context. Academy of Management Review, 16, 262-290.

Cooper, D., \& Schindler, P. (2010). Business Research Methods. McGraw-Hill Education.

DeNicolis-Bragger, J., Rodriguez-Srednicki, O., Kutcher, E. J., Indovino, L., \& Rosner, E. (2005). Work-Family Conflict, Work-Family Culture and Organizational Citizenship Behaviour among Teachers. Journal of Business and Psychology, 20(2), 303-324. http://dx.doi.org/10.1007/s10869-005-8266-0

Denison, D. R. (1990). Corporate Culture and Organizational Effectiveness. New York: John Wiley and Sons.

Elovainio, M., Kivimaki, M., \& Vahtera, J. (2002) Organizational Justice: Evidence of A New Psychosocial Predictor of Health. Am J Public Health, 92, 105-108. http://dx.doi.org/10.2105/AJPH.92.1.105 
Farh, J. L., Earley, P. C., \& Lin, S. C. (1997). Impetus for Action: A Cultural Analysis of Justice and Extra-Role Behaviour in Chinese Society. Administrative Science Quarterly, 42, 421-444. http://dx.doi.org/10.2307/2393733

Farh, J. L., Zhong, C. B., \& Organ, D. W. (2004). Organizational Citizenship Behaviour in the People's Republic of China. Organization Science, 15, 241-253. http://dx.doi.org/10.1287/orsc.1030.0051

Farh, J., Posdakoff, P., \& Organ, D. (1990). Accounting for Organizational Citizenship Behaviour: Leader Fairness and Task Scope Versus Satisfaction. Journal of Management, 16, 705-721. http://dx.doi.org/10.1177/014920639001600404

Farzin, F., Mohammadreza, A., Morad, R. D., \& Maryam, N. J. (2012). Organizational Citizenship Behaviour: The Role of Organizational Justice and Leader-Member Exchange, Interdisciplinary. Journal of Contemporary Research in Business, 3(9), 893-903.

Fok, L. Y., Hartman, S. J., Villere, M. F., \& Ralph, C. III. (1996). A Study of the Impact of Cross Cultural Differences on Perceptions of Equity and Organizational Citizenship Behaviour. International Journal of Management, 13, 3-15.

Folger, R., \& Cropanzano, R. (1998). Organizational Justice and Human Resource Management. Thousand Oaks, CA: Sage.

George, J. M., \& Brief, A. P. (1992). Feeling Good-Doing Good: A Conceptual Analysis of The Mood At Work-Organisational Spontaneity Relationship. Psychology Bulletin, 112, 310-329. http://dx.doi.org/10.1037/0033-2909.112.2.310

Gilliland, S. W., \& Chan, D. (2001). Justice in Organizations: Theory, Methods, and Applications. In N. Anderson, D. S. Ones, H. K. Sinangil \& C. Viswesvaran (Eds.), Handbook of Industrial, Work, and Organizational Psychology: Organizational Psychology (Vol. 2, pp. 143-165). Thousand Oaks, CA: Sage.

Gilliland, S. W., Benson, L. III., \& Schepers, D. H. (1998). A Rejection Threshold In Justice Evaluations: Effects on Judgment and Decision Making. Organizational Behaviour and Human Decision Processes, 76, 113-131. http://dx.doi.org/10.1006/obhd.1998.2801

Graham, J. W. (1989). Organizational Citizenship Behaviour: Construct Redefinition, Operationalization, and Validation. Loyola University of Chicago.

Graham, J. W. (1991). An Essay on Organizational Citizenship Behaviour. Employee Responsibilities and Rights Journal, 4, 249-270. http://dx.doi.org/10.1007/BF01385031

Greenberg, J. (1982). Approaching Equity and Avoiding Inequity in Groups and Organizations. In Greenberg \& Cohen (Eds.), Equity and Justice in Social Behaviour. New York: Academic Press.

Greenberg, J. (1990). Organizational Justice: Yesterday, Today, and Tomorrow. Journal of Management, 16, 399-432. http://dx.doi.org/10.1177/014920639001600208

Hair, J. F. J., Anderson, R. E., Tatham, R. L., \& Black, W. C. (1998). Multivariate Data Analysis with Readings (5th ed.).

Hofstede, G. (1980). Motivation, Leadership and Organization: Do American Theories Apply Abroad? Organizational Dynamics, 42-63. http://dx.doi.org/10.1016/0090-2616(80)90013-3

Hofstede, G. (1984). Cultures consequences. Newbury, CA: Sage Publication.

Hofstede, G. (2001). Culture's consequences: Comparing Values, Behaviours, Institutions, and Organizations across Nations (2nd ed.). Thousand Oaks: California: Sage Publications, Inc.

Ivancevich, J. M., \& Matterson, M. T. (2002). Organizational behaviour and management. McGraw-Hill.

Konovsky, M. A., \& Folger, R. (1991). The Effects of Procedural and Distributive Justice on Organisational Citizenship Behaviour. Paper presented at the annual meeting of the Academy of Management, Miami.

Konovsky, M. A., \& Organ, D. W. (1996). Dispositional and contextual determinants of organizational citizenship behaviour. Journal of Organizational Behaviour, 17(3), 253-266. http://dx.doi.org/10.1002/(SICI)1099-1379(199605)17:3<253::AID-JOB747>3.0.CO;2-Q

Krilowicz, T. J., \& Lowery, C. M. (1996). The Impact of Organizational Citizenship Behaviour on the Performance Appraisal Process: A cross-cultural Study. International Journal of Management, 13, 94-101.

Lau, R. S. Y. (2008). Integration and Extension of Leader-member Exchange and Organizational Justice at 
Individual and Group-Levels of Analysis. Ph.D Dissertation.

Lepine, J. A., Erez, A., \& Johnson, D. E. (2002). The Nature and Dimensionality of Organizational Citizenship Behaviour: A Critical Review and Meta-analysis. Journal of Applied Psychology, 87(1), 52-65. http://dx.doi.org/10.1037/0021-9010.87.1.52

Leventhal, G. S. (1976). Fairness in social relationship. In J. W. Thibaut, J. T. Spence \& R. C. Carson (Eds.), Contemporary Topics in Social Psychology (pp. 211-239). Morristown, NJ: General Learning Press.

Martin, C. L., \& Bies, R. J. (1991). Just laid off, but still a good citizen? Only if the process is fair. Paper Presented at the Annual Meeting of the Academy of Management. Miami, FL.

Moorman R. H. (1991). Relationship between Organizational Justice and Organizational Citizenship Behaviours: Do fairness perceptions influence employee citizenship? Journal of Applied Psychology, 76, 845-855. http://dx.doi.org/10.1037/0021-9010.76.6.845

Nasir, R., Mohammadi, M. S., Wan Shahrazad, W. S. O., Fatimah, R. K., \& Halim, F. (2011). Relationship between Organizational Citizenship Behaviour and Task Performance. The Social Sciences, 6(4), 307-312. http://dx.doi.org/10.3923/sscience.2011.307.312

Niehoff, B., \& Moorman, R. H. (1993). Justice as a Mediator of the Relationship between Methods of Monitoring and Organizational Citizenship Behaviour. Academy of Management Journal, 36(3), 527-556. http://dx.doi.org/10.2307/256591

Organ, D. W. (1988). Organizational Citizenship Behaviour: The Good Soldier Syndrome. Lexington, MA: Lexington Books.

Organ, D. W. (1990). The Motivational Basis of Organizational Citizenship Behaviour. In B. M. Staw \& L.L. Cummings (Eds.), Research in Organisational Behaviour (Vol. 12, pp. 43-72). Greenwich, CT: JAI.

Organ, D. W., \& Ryan, K. (1995). A meta-analytic review of attitudinal and dispositional predictors of organizational citizenship behavior. Personnel Psychology, 48, 775-802. http://dx.doi.org/10.1111/j.1744-6570.1995.tb01781.x

Pau Jung, J. Y., \& Hong, S. (2008). Organizational citizenship behaviour (OCB), TQM and performance at the Maquiladora. International Journal of Quality and Reliability Management, 25(8), 793-808. http://dx.doi.org/10.1108/02656710810898612

Podsakoff, P. M., \& MacKenzie, S. B. (1994). Organizational statutes for leadership really An Citizenship behaviour and sales unit effectiveness. Journal of Marketing Research, 3, 351-363.

Podsakoff, P. M., Ahearne, M., \& MacKenzie, S. B. (1997). Organizational citizenship behaviour and the quantity and quality for work group performance. Journal of Applied Psychology, 82, 262-270. http://dx.doi.org/10.1037/0021-9010.82.2.262

Podsakoff, P. M., MacKenzie, S. B., Moorman, R. H., \& Fetter, R. (1990). Transformational leader behaviours and their effects on followers' trust in leader, satisfaction, and organizational citizenship behaviours. Leadership Quarterly, 1, 42-107. http://dx.doi.org/10.1016/1048-9843(90)90009-7

Podsakoff, P. M., MacKenzie, S. B., Paine, J. B., \& Bachrach, D. G. (2000). Organizational citizenship behaviours: A critical review of the theoretical and empirical literature and suggestions for future research. Journal of management, 26, 513-563. http://dx.doi.org/10.1177/014920630002600307

Podsakoff, P. M., Niehoff, B. P., Mackenzie, S. B., \& Williams, M. L. (1993). Do substitute for leadership really substitute for leadership? An empirical examination of Kerr and Jermier's situational leadership model. Organizational Behaviour and Human Decision Processes, 54, 1-44. http://dx.doi.org/10.1006/obhd.1993.1001

Price, J. L., \& Mueller, C. W. (1986). Handbook of organizational measurement. Pitman, Marshfield, MA.

Skarlicki, D., \& Latham, G. (1996). Increasing citizenship behaviour within a labor union: A test of organizational justice theory. Journal of Applied Psychology, 81, 161-169. http://dx.doi.org/10.1037/0021-9010.81.2.161

Smith, C. A., Organ, D. W., \& Near, J. P. (1983). Organizational citizenship behaviour: Its nature and antecedents. Journal of Applied Psychology, 68(4), 653-663. http://dx.doi.org/10.1037/0021-9010.68.4.653

Storey, J. (2000). Human Resource Management: A Critical Text (2nd ed.). Thomson Learning.

Turnipseed, D. L., \& Mrukison, E. (2000). A bi-cultural comparison of organization citizenship behaviour: Does 
the OCB phenomenon transcend national culture? The International Journal of Organizational Analysis, 8 , 200-222. http://dx.doi.org/10.1108/eb028917

Wat, D., \& Shaffer, M. A. (2005). Equity and relationship quality influences on organizational citizenship behavior: the mediating role of trust in the supervisor and empowerment. Personnel Review, 34(4), 406-422. http://dx.doi.org/10.1108/00483480510599752

Weaver, G. R. (2001). The role of human resources in ethics/compliance management: a fairness perspective. Human Resource Management Review, 11(1/2). http://dx.doi.org/10.1016/S1053-4822(00)00043-7

Young, L. D. (2010). Is organizational justice enough to promote citizenship behaviour at work? A retest in Korea. European Journal of Scientific Research, 45(4), 637-648.

\section{Appendix}

\section{Dimensions of Organisational Justice}

Distributive Justice: Based on the works of Nichoff and Moorman (1993) and Price and Mueller (1986) a structured questionnaire was developed. The scale was based on the degree to which the respondent agreed with the following statements concerning the distribution of the rewards and organisational favours:

i. Rewards in this organisation are distributed based on merit. That is the people who work hardest or produce the most should get the greatest rewards (equity norm).

ii. Every member gets the same share of rewards, regardless of effort (the notion of equality).

iii. Every member receives rewards in proportion to their needs (the need norm).

iv. I get rewards that I expect

v. I get rewards that I deserve

vi. My supervisor has fairly rewarded me when I consider the responsibilities I have.

vii. My supervisor has fairly rewarded me when I take into account the amount of education and training that I have.

viii. My supervisor has fairly rewarded me when I consider the stresses and strains of my job.

ix. My supervisor has fairly rewarded me when I consider the work that I have done well.

Procedural Justice: Based on the work of Elovainio, Kivimäki, and Vahtera (2002); Nichoff and Moorman (1993) and Moorman, (1991) a structured questionnaire was developed. The scale was based on the degree to which the respondent agreed with the following statements concerning the methods process, and procedures used at the workplace:

i. Job decisions are made by my supervisor in an unbiased manner.

ii. My supervisor makes sure that all employees concerns are heard before job decisions are made.

iii. To make job decision, my supervisor collects accurate and complete information necessary for making decisions.

iv. My supervisor clarifies decisions and provides additional information when requested by employees.

v. Employees are allowed to challenge or appeal job decisions made by my supervisor.

vi. Procedures are designed to generate standards so that decisions can be made with consistency.

vii. All job decisions are applied consistently across all affected employees.

Interactional Justice: Based on the works of Elovainio, Kivimäki, and Vahtera (2002); Moorman (1991); Nichoff and Moorman (1993) and Price and Mueller (1986) a structured questionnaire was developed. The scale was based on the following statements about the general behaviour of the respondent's supervisor:

i. When decisions are made about my job, my supervisor treats me with kindness and consideration.

ii. When decisions are made about my job, my supervisor treats me with respect and dignity.

iii. When decisions are made about my job, my supervisor is sensitive to my personal needs.

iv. When decisions are made about my job, my supervisor deals with me in a truthful manner.

v. When decisions are made about my job, my supervisor considers my viewpoint and treats me fairly. 
vi. When decisions are made about my job, my supervisor shows concern for my rights as an employee.

vii. Concerning decisions about my job, my supervisor discusses the implications of the decision with me.

viii. My supervisor is able to suppress personal biases.

ix. My supervisor does not play favourites.

x. My Co-workers does not put each other down.

All the three dimensions of organisational justice were measured on a 5- point Likert type scale. The response mode ranges from $5=$ strongly agree to $1=$ strongly disagree.

\section{Copyrights}

Copyright for this article is retained by the author(s), with first publication rights granted to the journal.

This is an open-access article distributed under the terms and conditions of the Creative Commons Attribution license (http://creativecommons.org/licenses/by/3.0/). 